\title{
Key criteria for the design of polymeric stabilizers for aqueous titanium dioxide dispersions of high solid content
}

\author{
Serge Creutz ${ }^{1}$, Robert Jérôme * \\ ${ }^{1}$ Current address: Dow Corning S.A., Parc Industriel, B-7180 Seneffe, Belgium \\ ${ }^{2}$ Center for Education and Research on Macromolecules (CERM), University of \\ Liège, Sart-Tilman, B6, BE-4000 Liège, Belgium; Fax (32)4-3663497; \\ rjerome@ulg.ac.be
}

(Received: May 29, 2001; published: August 29, 2001)

\begin{abstract}
Amphiphilic copolymers consisting of an aminated hydrophobic block and a hydrophilic poly(sodium methacrylate) one have been synthesized with different structures and tested as stabilizers for aqueous dispersions of alumina coated titanium dioxide ( $80 \mathrm{wt} .-\%$ solid). The dispersion stability is ruled by the strength of the anchoring of the aminated block onto the pigment and by the dynamics of the micelles formed by the copolymer. Any decrease in the anchoring strength, for example as a result of higher steric hindrance for the adsorbing block or of random rather than blocky distribution of the aminated co-units, is detrimental to the dispersion stability and makes this stability more dependent on the copolymer composition. Indeed, the position and dynamics of the unimers $\leftrightarrows$ micelles equilibrium then control the adsorption of the copolymer on the pigment during the grinding process.
\end{abstract}

\section{Introduction}

A large variety of products on the market are based on dispersions of solid particles in liquids [1-8], which requires the availability of efficient stabilizers to build up either a steric or an electrostatic barrier against flocculation around the particles $[9,10]$. The current market trend being to increase the solid content as much as possible and to replace organic solvents by water, there is a need for dispersants better suited than the traditional surfactants. Nowadays, amphiphilic polymers, i.e. chains containing hydrophilic and hydrophobic segments, are the best answer to this challenge. As a rule, block copolymers of appropriate composition and molecular weight are ideal additives to control the interfacial properties of any multiphase systems.

Compatibilization of immiscible polymer blends is a well known example [11]. Control of the crystallization of inorganic particles $\left(\mathrm{CaCO}_{3}, \mathrm{ZnO}\right)$ [12], formation of micro- or nanoparticles for drug encapsulation are other non-limiting examples [13]. The reader can find more information in recent reviews [14]. The purpose of this paper is to emphasize how the structure of copolymers of hydrophilic sodium methacrylate (precursor of the stabilizing component) and hydrophobic tert-amine containing monomer (precursor of the anchoring block) influences the stability of aqueous $\mathrm{TiO}_{2}$ dispersions of high solid content. 


\section{Experimental part}

\section{Materials}

The block copolymers were anionically synthesized as reported elsewhere [15-19].

The molecular characteristics of these block copolymers are listed in Tab. 1.

Tab. 1. Characteristics of the copolymers used in this contribution

\begin{tabular}{|c|c|c|c|c|c|c|}
\hline Code & Comonomers & $\begin{array}{l}\text { Number } \\
\text { of units of } \\
\text { the blocks }\end{array}$ & $\begin{array}{c}M_{\mathrm{n}} \\
\text { (total) }\end{array}$ & $\begin{array}{c}\text { NMR } \\
\text { composition } \\
\text { in wt.-\% }\end{array}$ & $M_{\mathrm{w}} / M_{\mathrm{n}}$ & $\begin{array}{l}\mathrm{cmc}^{\mathrm{a})} \\
\text { in } \mathrm{mg} / \mathrm{l}\end{array}$ \\
\hline$D_{34}$ & DMAEMA- $b$-tBMA & $23-49$ & 10600 & $34-66$ & 1.1 & 120 \\
\hline $\mathrm{D}_{15}$ & DMAEMA- $b$-tBMA & $16-101$ & 16800 & $15-85$ & 1.2 & 120 \\
\hline $\mathrm{VP}_{19}$ & 4VP-b-tBMA & $27-85$ & 14800 & $19-81$ & 1.2 & 11 \\
\hline $\mathrm{VP}_{30}$ & 4VP-b-tBMA & $30-53$ & 10700 & $30-70$ & 1.2 & 5 \\
\hline $\mathrm{Rd}$ & $\begin{array}{c}\text { DMAEMA/tBMA } \\
\text { (random) }\end{array}$ & & 17000 & $35-65$ & 1.7 & 340 \\
\hline $\mathrm{Tp}$ & $\begin{array}{c}\text { DMAEMA/tBMA } \\
\text { (tapered) }\end{array}$ & & 7400 & $36-64$ & 1.1 & 75 \\
\hline$E_{37}$ & DEAEMA- $b$-tBMA & $19-43$ & 9700 & $37-63$ & 1.1 & 42 \\
\hline $\mathrm{E}_{18}$ & DEAEMA- $b$-tBMA & $18-105$ & 18300 & $18-82$ & 1.05 & 125 \\
\hline$E_{\text {out34 }}$ & $\begin{array}{c}\text { DEAEMA- } b \text {-tBMA- } \\
b \text {-DEAEMA }\end{array}$ & $9-46-9$ & 9900 & $34-66$ & 1.1 & 44 \\
\hline $\mathrm{B}_{39}$ & tBAEMA- $b$-tBMA & $18-37$ & 8700 & $39-61$ & 1.05 & 14 \\
\hline $\mathrm{B}_{17}$ & tBAEMA- $b$-tBMA & $14-86$ & 14700 & $17-83$ & 1.05 & 47 \\
\hline$B_{\text {out35 }}$ & $\begin{array}{c}\text { tBAEMA- } b \text {-tBMA- } \\
b \text {-tBAEMA }\end{array}$ & 8-39-8 & 8500 & $35-65$ & 1.1 & 17 \\
\hline $\mathrm{MM}_{19}$ & MMA- $b$-tBMA & $16-48$ & 8400 & $19-81$ & 1.05 & 17 \\
\hline $\mathrm{MM}_{34}$ & MMA- $b$-tBMA & $22-30$ & 6500 & $34-66$ & 1.05 & 5 \\
\hline GMA & MMA- $b-G M A$ & $16-45$ & 8000 & $20-80$ & 1.05 & 10 \\
\hline
\end{tabular}

a) Critical micelle concentration, measured after derivatization of the poly(tert-butyl methacrylate) (PtBMA) block into poly(sodium methacrylate) (PMANa).

DMAEMA: 2-(dimethylamino)ethyl methacrylate; DEAEMA: 2-(diethylamino)ethyl methacrylate; tBAEMA: 2-(tert-butylamino)ethyl methacrylate; 4VP: 4-vinylpyridine; MMA: methyl methacrylate; GMA: glycidyl methacrylate.

\section{Preparation of $\mathrm{TiO}_{2}$ dispersions}

Titanium dioxide, RCL 535 from SCM Chemicals, was of the rutile type. It was precoated with alumina and characterized by a surface area of $12 \mathrm{~m}^{2} / \mathrm{g}$ and a density of $4.2 \mathrm{~g} / \mathrm{cm}^{3}$. 
To $50 \mathrm{ml}$ of an aqueous solution of copolymer (in demineralized water at pH 9), $200 \mathrm{~g}$ of titanium dioxide were added and ground with a dissolver disk at a speed rate of 3700 r.p.m. for $15 \mathrm{~min}$ (volume fraction of $\mathrm{TiO}_{2}=0.48$ ). The copolymer content was changed and referred to as the weight ratio with respect to titanium dioxide (e.g., $1 \mathrm{~g}$ dispersant for $200 \mathrm{~g} \mathrm{TiO}_{2}$ is reported as $0.5 \%$ ) [15].

\section{Rheological measurements}

Rheology of the dispersions was measured with a Rheotest 2 equipped with a Couette cell at $25^{\circ} \mathrm{C}$. Data reported were steadystate values. The lower the viscosity, the more stable the dispersion [15].

\section{Results}

It must be noted that $\mathrm{TiO}_{2}$ is added to a concentrated aqueous solution of the copolymer, at least $5-20 \mathrm{~g} / \mathrm{l}$, such that micelles are the major species formed by the dispersant. These micelles are nothing but reservoirs of copolymer chains (unimers) that have to be adsorbed on the pigment [15] within the 15 min period of grinding time. The position of the unimers $\leftrightarrows$ micelles equilibrium thus determines the amount of copolymer chains which can be adsorbed immediately on the pigment. If additional unimers are required to completely cover the solid surface, then the dynamics of the unimers $\leftrightarrows$ micelles equilibrium will control the release of the unimers. Therefore, the stability of the final dispersion will be the result of a complex interplay of thermodynamics (thermodynamics of micellization and adsorption) and kinetics (dynamics of the micellization equilibrium, adsorption rate) including the influence of the mechanical energy brought by the grinding, as tentatively illustrated in Scheme 1.

Scheme 1:
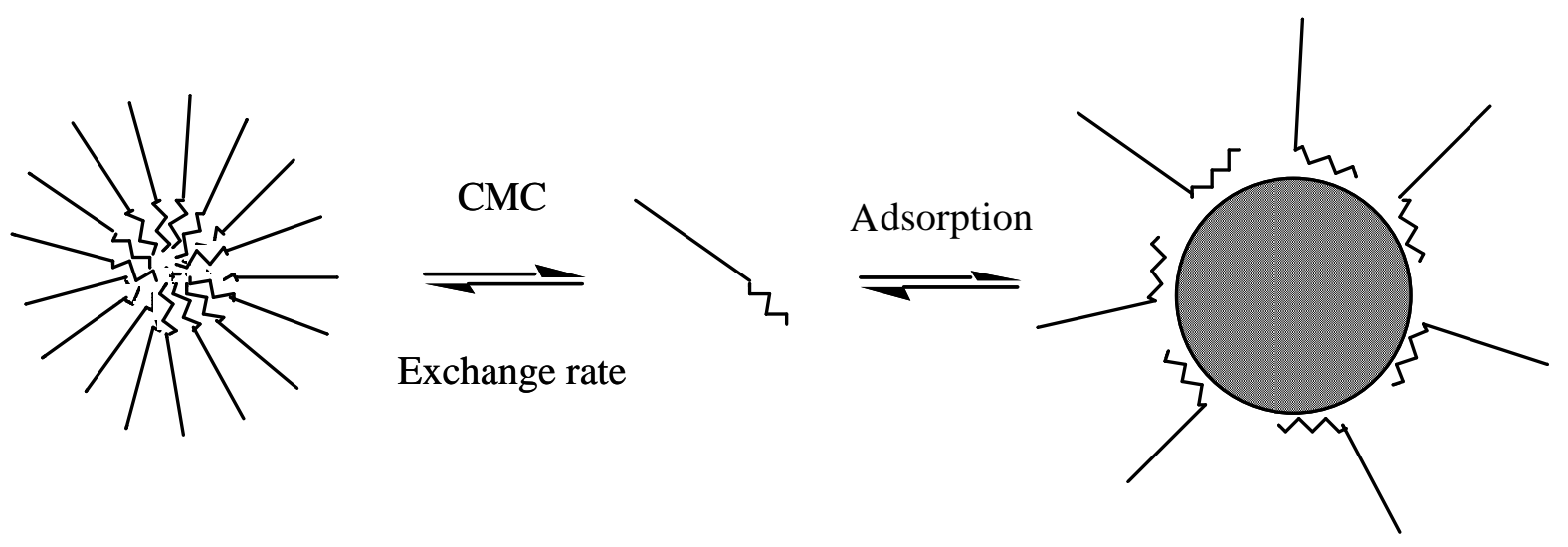

The pigment used in this study being alumina-coated titanium dioxide, the hydroxyl groups and the Al cations on the surface are the potential sites of adsorption. Therefore, the adsorption is expected to occur first onto the stronger anchoring sites (Al cations) and then on the less energetically favorable sites ( $\mathrm{OH}$ groups), as reported elsewhere $[20,21]$. Nevertheless, the question of the availability of these sites to the copolymer must be addressed, because the Al cations lie beneath the hydroxyl groups [22], which makes the adsorption on them very sensitive to steric effects. 
That the dispersion stability depends on the anchoring strength of the dispersant to the pigment has been demonstrated by comparing two diblock copolymers consisting of a stabilizing poly(sodium methacrylate) block and an anchoring block which is either poly(2-(dimethylamino)ethyl methacrylate) (PDMAEMA) or poly(4-vinylpyridine) (P4VP). The capability of the PDMAEMA-containing copolymers to stabilize the dispersion strongly depends on the composition, in contrast to the diblocks which contain P4VP $\left(\mathrm{VP}_{19}\right.$ vs. $\left.\mathrm{VP}_{30}\right)$. Fig. 1 shows indeed that the minimum in the dispersion viscosity, which is directly related to the fineness of the dispersion that the copolymer has allowed to reach, is essentially independent of the composition in case of the P4VP adsorbing block (19 vs. 30 wt.-\% of P4VP), whereas a dramatic increase (ca. 2 orders of magnitude) is observed when the PDMAEMA content of the diblocks is decreased from 34 to $15 \mathrm{wt} . \%$. A reasonable explanation is that the aliphatic amine in PDMAEMA is more sterically hindered than in P4VP, such that the PDMAEMA blocks would basically interact by $\mathrm{H}$-bonding with the hydroxyl groups of the alumina coating, in contrast to the P4VP blocks that could interact more strongly with the Lewis acid sites of the solid surface. This argument is strengthened by the adsorption free energy reported by van den Haak et al. $[23,24]$ for 2-ethylpyridine and triethylamine onto iron oxide at the surface of which only Lewis acid sites are available [25]. This energy is indeed $-10.2 \mathrm{~kJ} / \mathrm{mol}$ in case of the pyridine derivative compared to $-0.3 \mathrm{~kJ} / \mathrm{mol}$ for the aliphatic tertiary amine.

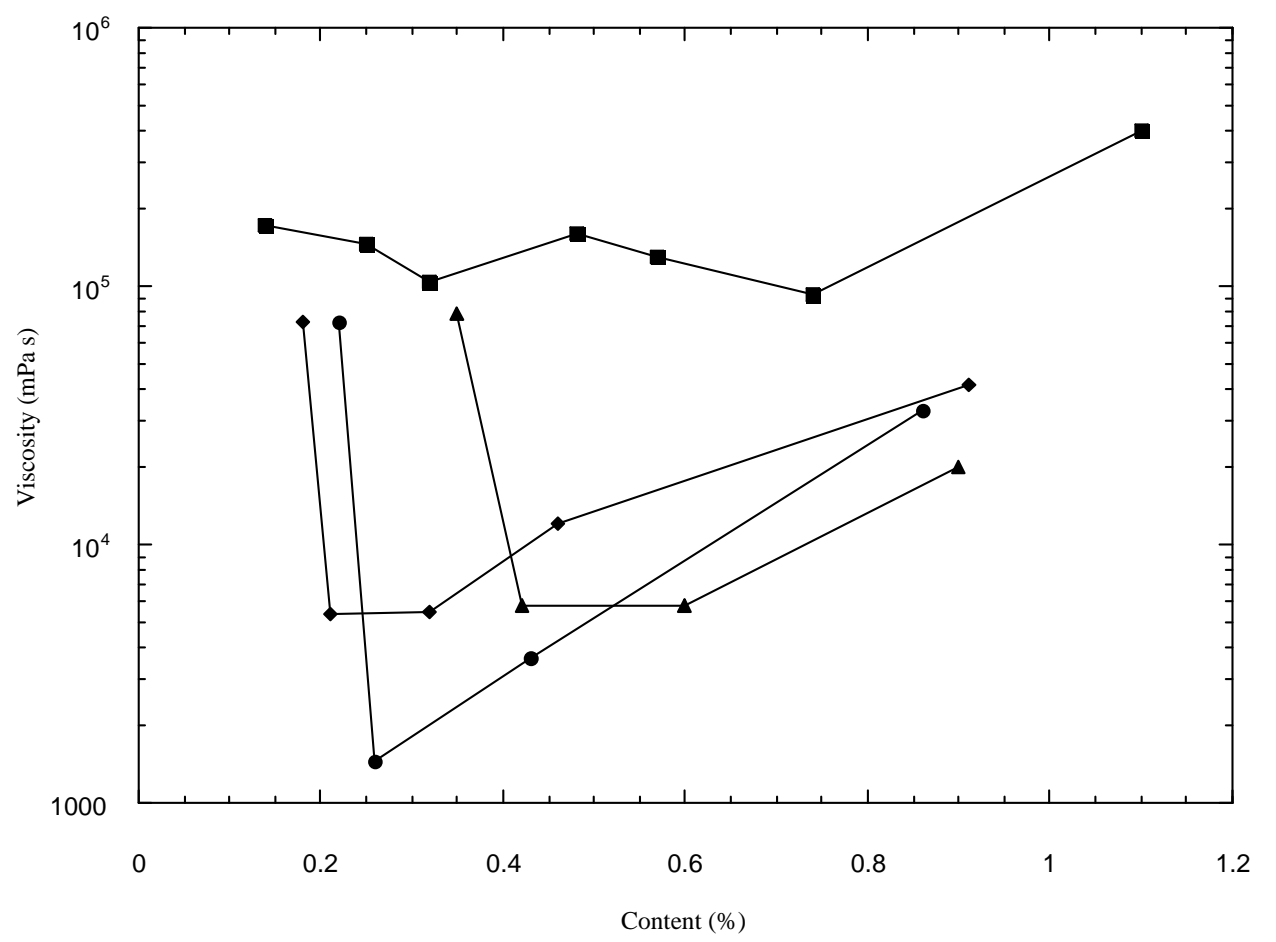

Fig. 1. Plot of the viscosity at $0.54 \mathrm{~s}^{-1}$ vs. the dispersant/pigment ratio (e.g., $1 \mathrm{~g}$ dispersant for $200 \mathrm{~g} \mathrm{TiO}_{2}$ is reported as $0.5 \%$ ). $\bullet \mathrm{D}_{34}, \mathrm{D}_{15}, \bullet \mathrm{VP}_{19}, \boldsymbol{\Delta} \mathrm{VP}_{30}$. The solid lines are merely guides for the eyes

For the same comonomer pair, the anchoring of the copolymer to the pigment can be depressed merely by changing the comonomer distribution from a blocky (diblock) to a random one. Indeed, the propensity of the anchoring units to stick to the solid surface is then more severely challenged by the tendency of the charged NaMA units 
to stay in the aqueous phase. As expected, the random copolymer, Rd, is by far less efficient than the diblock equivalent, $D_{34}$ (Fig. 2) [19]. The capability of the copolymer to disperse the pigment in a stable way is rapidly restored when a tapered diblock copolymer (Tp) is used, which consists of two main PMANa and PDMAEMA blocks connected one to each other by a transient block of a regularly changing composition (Fig. 2) [19].

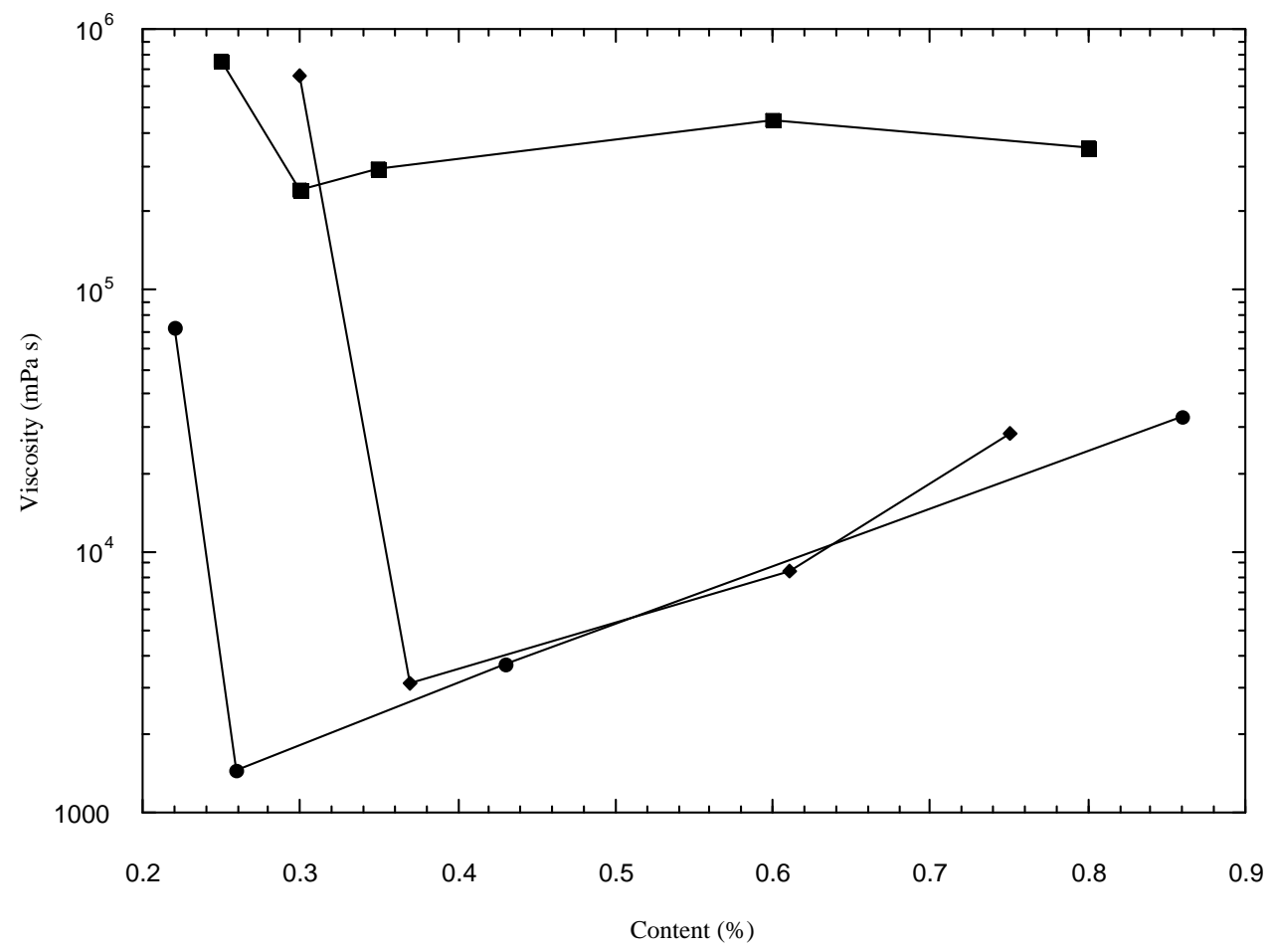

Fig. 2. Plot of the viscosity at $0.54 \mathrm{~s}^{-1}$ vs. the dispersant/pigment ratio. $\bullet \mathrm{D}_{34}, \boldsymbol{R d}$, - Tp. The solid lines are merely guides for the eyes

The steric hindrance of the aliphatic tertiary amine of the anchoring block has been increased further by replacing the dimethylamino group $\left(D_{34}\right)$ by a diethylamino one $\left(E_{37}\right)$ and finally by the very bulky tert-butylamino group $\left(B_{39}\right)$. There is a direct parallelism between the dispersion stability and the adsorption of the copolymer to the pigment (Fig. 3). At comparable composition and molecular weight, the PDMAEMA block is strongly anchored $\left(D_{34}\right)$ whereas the PDEAEMA block is a poor anchoring block $\left(E_{37}\right)$. The tert-butylamino groups cannot anchor the hydrophobic block to the solid surface $\left(\mathrm{B}_{39}\right)$, no stable dispersion being formed. It must be noted that in addition to the bulkiness of the aminated groups, the hydrophobicity of the anchoring block is also increased, which results in a lower cmc (less free unimers) (Tab. 1) and slower release of the unimers from the micelles [26,27], which is detrimental to the dispersion stabilization. 


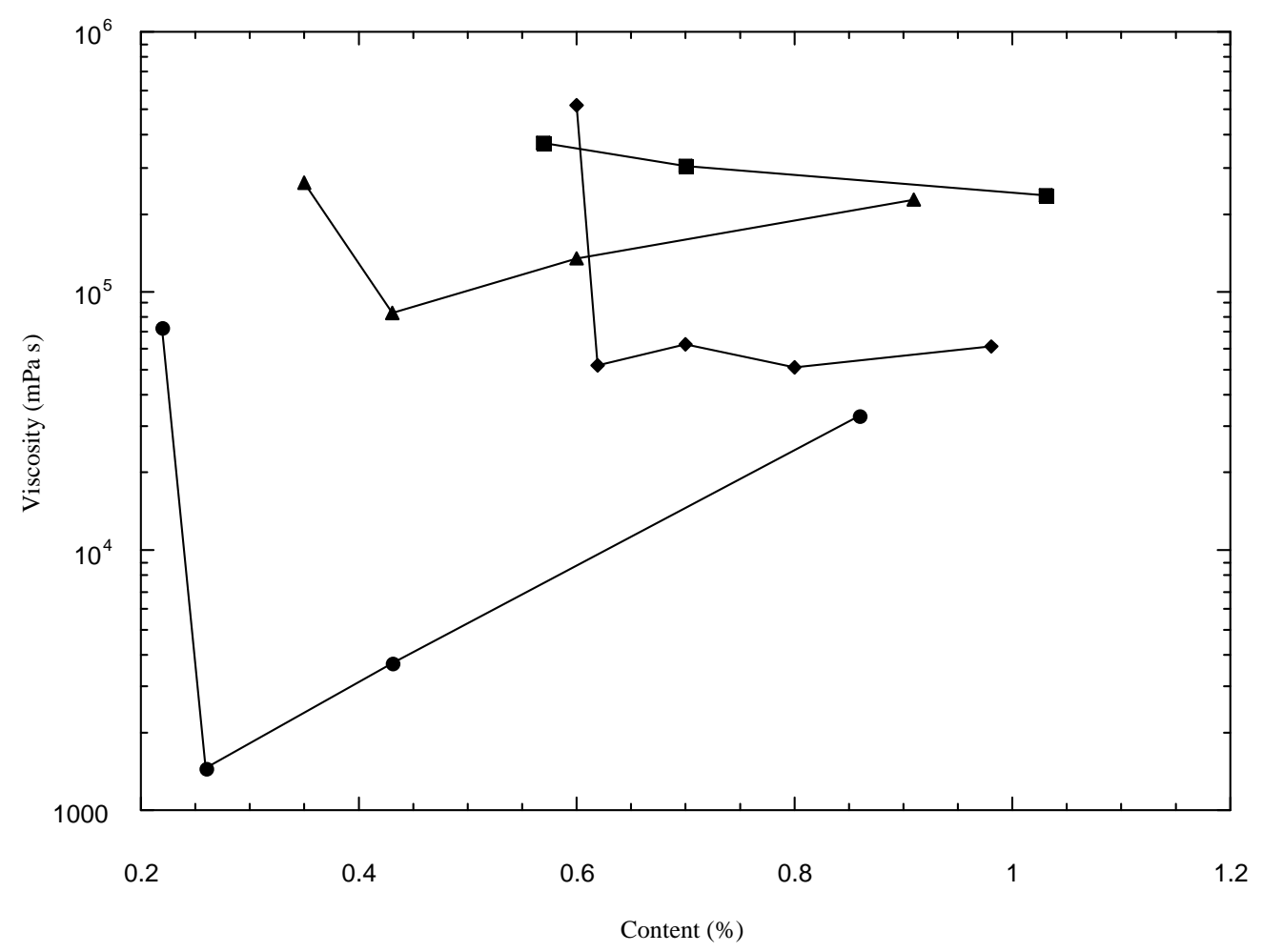

Fig. 3. Plot of the viscosity at $0.54 \mathrm{~s}^{-1}$ vs. the dispersant/pigment ratio. $\bullet D_{34}, \boldsymbol{E} E_{37}$, $-E_{18}, \Delta B_{17}$. The solid lines are merely guides for the eyes

We have been interested in increasing the $\mathrm{cmc}$ and the release of the copolymer chains from the micelles in order to confirm that the availability of free chains and the rate at which they are made available are essential to prepare stable dispersions. For this purpose, the weight ratio of the stabilizing over the anchoring blocks has been increased and triblocks with outer anchoring blocks have been used instead of diblocks. These triblocks form indeed less stable micelles because of the bending of the inner PMANa block as result of the contribution of the outer blocks to the micellar core. Although a higher content of the hydrophilic block in diblocks should be detrimental to the adsorption of the copolymer, the dispersion of $\mathrm{TiO}_{2}$ is improved, at least in the case of the poly(2-(diethylamino)ethyl methacrylate) $\left(E_{18}\right)$ and the poly(2(tert-butylamino)ethyl methacrylate) $\left(B_{17}\right)$ anchoring blocks (Fig. 3). Let us note that the same modification when the anchoring block is PDMAEMA has the opposite effect $\left(D_{15}\right.$ vs. $D_{34}$, in Fig. 1), consistently with the constancy of the $\mathrm{cmc}$ (Tab. 1). Although the risk for the particle to be bridged and to flocculate cannot be precluded in case of the triblocks ( $\mathrm{E}_{\text {out34, }}, \mathrm{B}_{\text {out35 }}$ ), the dispersion stabilization is improved compared to the parent diblocks ( $\mathrm{B}_{\text {out35 }} \mathrm{vs}$. $\mathrm{B}_{39}$ which is unable to stabilize the dispersion; $E_{340 u t} v s . E_{37}$ ) (Fig. 4). These examples highlight that in addition to the thermodynamic control, the capability of amphiphilic copolymers to stabilize dispersions of solid particles also depends on the dynamics of the micellization equilibrium.

The kinetic control has however a minor role in case of the strongly anchoring P4VP block. In order to show that this observation might be general, the P4VP block has been substituted by PMMA on the basis of data published by van den Haak et al. Indeed, the free energy of adsorption of methyl propionate onto iron oxide is 


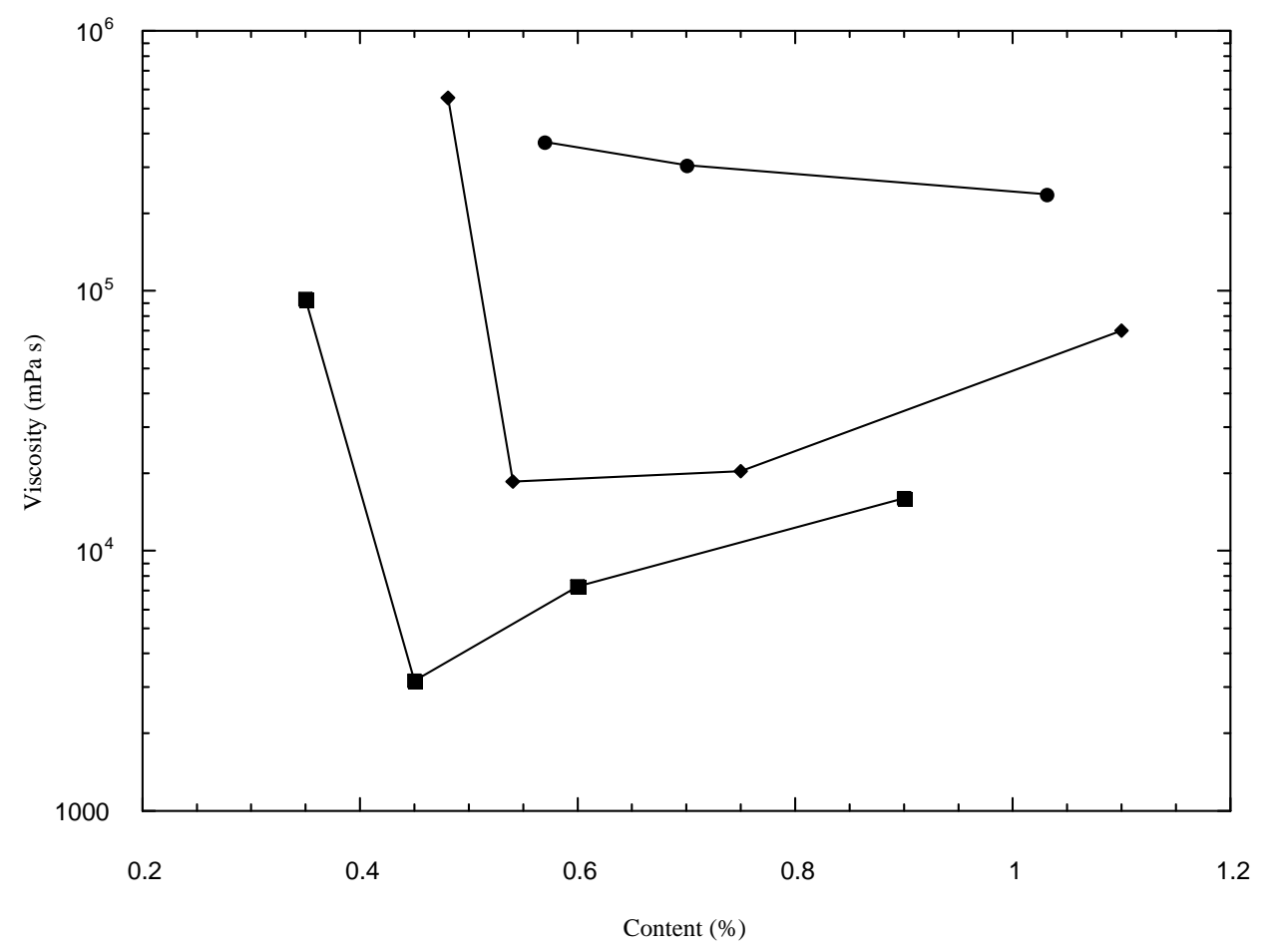

Fig. 4. Plot of the viscosity at $0.54 \mathrm{~s}^{-1}$ vs. the dispersant/pigment ratio. $\bullet \mathrm{E}_{37}, \boldsymbol{E} \mathrm{E}_{\text {out34, }}$ - $\mathrm{B}_{\text {out35. }}$. The solid lines are merely guides for the eyes

$-12.5 \mathrm{KJ} / \mathrm{mol}$ vs. $-10.2 \mathrm{KJ} / \mathrm{mol}$ for 2-ethylpyridine $[23,24]$, which supports that PMMA should also be strongly adsorbed on the alumina coating of $\mathrm{TiO}_{2}$. As expected, the PMMA containing diblocks are efficient dispersants, independently of their composition (Fig. 5; MM19 vs. MM34). Conversely, the substitution of a sulfonated poly (glycidyl methacrylate) block for the PMANa leads to micelles with an extremely slow dynamics of exchange at room temperature [28]. No stable dispersion could be prepared in the presence of this type of copolymer, which is another extreme situation which illustrates the decisive role of the kinetic control.

\section{Conclusion}

This short discussion has highlighted the key role of the anchoring of the hydrophobic block of amphiphilic copolymers on the surface of particles to be dispersed in water $[15,19]$. However, the dynamics of the micelles formed by the copolymer has also a decisive influence on the stabilization of the dispersions, a low $\mathrm{cmc}$ and/or slow exchange of the copolymer chains being detrimental to the dispersion stability, particularly when the anchoring of the copolymer to the solid particles is not exceedingly strong. As a rule, the ideal amphiphilic copolymer has a blocky structure, being a pure or a tapered diblock rather than a triblock. When the choice of the comonomers is concerned, the stabilizing block should be a polyelectrolyte, and the anchoring block should have a strong propensity to interact with the solid surface, thus with the most strongly anchoring sites when several types are available on the surface. Finally, the micelles formed by the "ideal" dispersant should be loose enough, which means a high $\mathrm{cmc}$ and a fast exchange between unimers and 


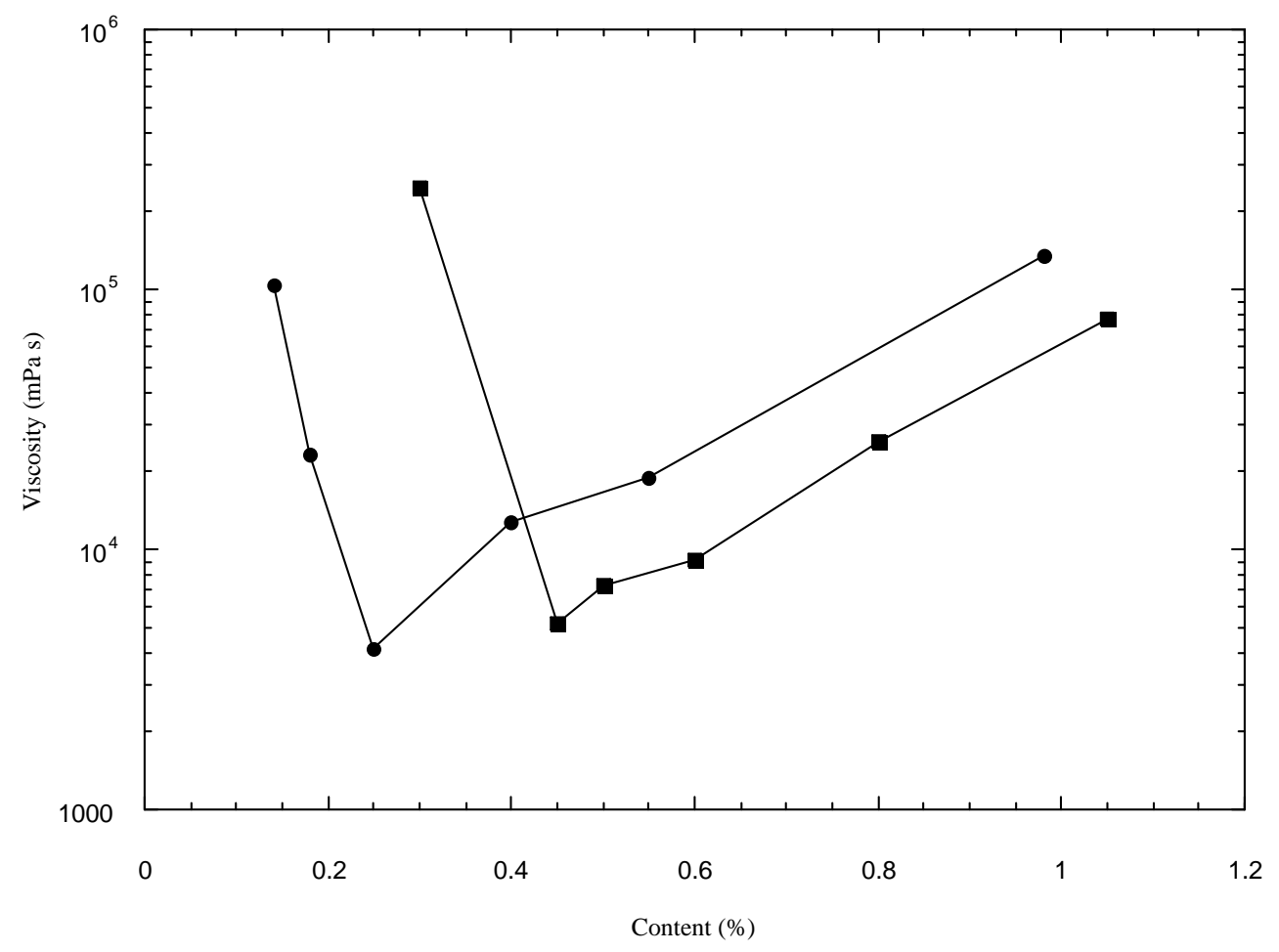

Fig. 5. Plot of the viscosity at $0.54 \mathrm{~s}^{-1} \mathrm{vs}$. the dispersant/pigment ratio. $\bullet \mathrm{MM}_{19}$, - $\mathrm{MM}_{34}$. The solid lines are merely guides for the eyes

micelles. Therefore, increasing the copolymer molecular weight at constant composition is unfavorable to the dispersion stability as result of a slower exchange. The micellar dynamics is more likely the most important parameter for the design of versatile polymeric dispersants, because it is quite a problem to find out a block able to interact strongly with any type of solid particles. Finally, it must be mentioned that the dynamics of the copolymer micelles can be modulated by the addition of traditional surfactants, e.g. sodium dodecyl sulfate [29]. This combination is a valuable strategy to extend the range of application of polymeric dispersants.

Acknowledgement: The authors are grateful to Akzo Nobel Coatings Technology Center, Pigments and Pigment Dispersing Agents, for financial support. They also thank the "Services Fédéraux des Affaires Scientifiques, Techniques et Culturelles" for general support to CERM in the frame of the "Pôles d'Attraction Interuniversitaires 4/11: Supramolecular Chemistry and Catalysis". Fruitful discussions with Prof. F. C. De Schryver, Prof. Ph. Teyssié and Dr. J. Van Stam are warmly acknowledged.

[1] Tadros, Th. F.; Taylor, P.; Bognolo, G.; Langmuir 1995, 11, 4678.

[2] Gebhardt, J. E.; Fuerstenau, D. W.; Colloids Surf. 1983, 7, 221.

[3] Patton, T. C.; "Paint Flow and Pigment Dispersion", 2nd Edn., Wiley, New York 1979.

[4] Leemans, L.; Fayt, R.; Teyssié, Ph.; Uytterhoeven, H.; Polymer 1990, 31, 106. 
[5] Lee, H.; J. Colloid Interface Sci. 1993, 159, 210.

[6] de Laat, A. W. M.; Ph.D. Thesis, Wageningen Agricultural University, the Netherlands 1995.

[7] Hunter, R. J.; "Foundations of Colloid Science", Oxford University Press, New York 1989.

[8] Alexandridis, P.; Colloid Interface Sci. 1996, 1, 490.

[9] Napper, D. H.; "Polymeric Stabilization of Colloidal Dispersion", Academic Press, New York 1983.

[10] Everett, D. H.; "Basic Principles of Colloid Science", Royal Society of Chemistry 1988.

[11] Paul, D. R.; "Polymer Blends", Paul, D. R., Newman, S., editors, Academic Press, New York 1978, vol. 2, pp. 35-62.

[12] Oner, M.; Norwig, J.; Meyer, W. H.; Wegner, G.; Chem. Mater. 1998, 10, 460.

[13] de Jaeghere, F.; Alleman, E.; Feijen, J.; Kissel, T.; Doelker, E.; Gurny, R.; J. Drug Targeting 2000, 8, 143.

[14] (a) Förster, S.; Antionietti, M.; Adv. Mater. 1998, 10, 195; (b) Cölfen, H.; Macromol. Rapid. Commun. 2001, 22, 219.

[15] Creutz, S.; Jérôme, R.; Langmuir 1999, 15, 7145.

[16] Creutz, S.; Teyssié, Ph.; Jérôme, R.; Macromolecules 1997, 30, 1.

[17] Creutz, S.; Teyssié, Ph.; Jérôme, R.; Macromolecules 1997, 30, 6.

[18] Creutz, S.; Teyssié, Ph.; Jérôme, R.; J. Polym. Sci. A: Polym. Chem. 1997, 35, 2035.

[19] Creutz, S.; Jérôme, R.; submitted for publication.

[20] Healy, M. H.; Wieserman, L. F.; Arnett, E. M.; Wefers, K.; Langmuir 1989, 5, 114.

[21] Gervasini, A.; Auroux, A.; J. Phys. Chem. 1993, 97, 2628.

[22] Koubek, J.; Volf, J.; Pasek, J.; J. Catal. 1975, 38, 385.

[23] van den Haak, H. J. W.; Schöps, M.; Adler, H. J. P.; Fietzek, C.; Montagut, J. Macromol. Symp. 1997, 126, 253.

[24] van den Haak, H. J. W.; J. Coat. Techn. 1997, 69, 137.

[25] Sokoll, R.; Hobert, H.; Schmuck, I.; J. Catal. 1990, 121, 153.

[26] Creutz, S.; van Stam, J.; Antoun, S.; De Schryver, F. C.; Jérôme, R.; Macromolecules 1997, 30, 4078.

[27] Creutz, S.; van Stam, J.; De Schryver, F. C.; Jérôme, R.; Macromolecules 1998, 31,681 .

[28] Creutz, S.; van Stam, J.; Antoun, S.; De Schryver, F. C.; Jérôme, R.; manuscript in preparation.

[29] van Stam, J.; Creutz, S.; De Schryver, F. C.; Jérôme, R.; Macromolecules 2000, 33, 6388. 